\title{
Redox-driven shifts in soil microbial community structure in the drawdown zone after construction of the Three Gorges Dam
}

\author{
Shuling Wang ${ }^{1}$, Sarwee J. Faeflen ${ }^{1}$, Alan L. Wright ${ }^{2}$, Xia Zhu-Barker ${ }^{3}$, Xianjun Jiang ${ }^{1,{ }^{*}}$ \\ 1 College of Resources and Environment, Southwest University, Chongqing 400715, China \\ 2 Indian River Research \& Education Center, University of Florida, Fort Pierce, FL 34945, USA \\ 3 Department of Land, Air and Water Resources, University of California Davis, CA 95616, USA
}

\section{ARTICLE INFO}

\section{Article history:}

Received June 18, 2018

Revised October 3, 2018

Accepted October 9, 2018

\section{Keywords:}

Water fluctuation zone

Redox disturbance

Microbial community structure

Phospholipid fatty acids (PLFA)

Three Gorges Reservoir

\begin{abstract}
A B S T R A C T
Soil redox is a critical environmental factor shaping the microbial community structure and ultimately alters the nutrient cycling. However, the response of soil microbial community structure to prolonged or repeated redox fluctuations is not yet clear. To study the dynamic effects of prolonged redox disturbances to the soil microbial community structure, soil samples experiencing 8, 5 and 0 alternating oxic-anoxic cycles within approximately 6 months each year were collected and the microbial community structure were evaluated using phospholipid fatty acid analysis (PLFA) profiles. Prolonged redox disturbances had significant effects on soil physiochemical properties and soil microbial community structure. The relative abundance of straight chain saturated PLFAs, cyclopropyl, and terminal- and mid-branched chain saturated PLFAs increased due to prolonged redox disturbances, but there was a consistent decrease in linear monounsaturated PLFAs and polyunsaturated PLFAs in the fluctuating zone. Prolonged redox disturbances had a negative impact on the total PLFA content (a proxy for biomass). Both the fluctuating zone (8-cycle and 5-cycle plots) and the never flooded zone (0-cycle plots) were dominated by Gram-positive bacteria and a low content of fungi, actinomycetes and protozoa. The fungi and protozoa abundance decreased significantly with an increase in the occurrence of alternating flooding-dry events, suggesting that the prolonged redox disturbance leads to high stress on the fungi and protozoa populations. Moreover, total organic matter (TOC) and C:N ratio, environmental factors that can be influenced by recurring redox fluctuations, also influenced the microbial community structure.
\end{abstract}

(c) Higher Education Press 2019

\section{Introduction}

Soil redox potential, associated with most soil properties and processes, is considered an important factor influencing soil microbial composition, diversity and community structure

\footnotetext{
* Corresponding author

E-mail address: jiangxj@swu.edu.cn (X.J. Jiang)
}

(Heintze, 1934; Lüdemann et al., 2000; Song et al., 2008). Each microorganism type is compatible with specific redox conditions and is characterized by its ability to develop within a defined range of Eh values. Fluctuating redox conditions are indeed primary features in natural ecosystems as changes in external conditions (e. g., precipitation, water table, temperature, and variability of organic matter) can directly impact soil redox potential. Shifts in soil redox can occur on very short (minute, hourly or daily) (Satpathy et al., 1997; Silver et al., 
1999; Nikolausza et al., 2008) to longer (monthly, seasonally) timescales (Teichert et al., 2000; Moche et al., 2015). Flooding, which has direct effects on soil oxygen and nutrients, is considered the most important factor causing rapid shifts, including temporal and spatial variations in redox conditions (Haberer et al., 2012). The frequency of redox shifts caused by flooding has a strong effect on the microbial community, as the changes due to alternating flooding and drying lead to varying amounts of electron donors and acceptors necessary for microbial growth and functioning (Fierer and Schimel, 2002; Balasooriya et al., 2013). Fluctuation of water levels is a major dynamic in ecosystems surrounding the Three Gorges Reservoir in China. In the zone of water fluctuation, periodic redox changes are known to occur due to seasonal water level control regulation. The reservoir has a period of drainage in summer from May to September with the water level reaching its lowest point of $145 \mathrm{~m}$. The reservoir is then flooded again from October to April with the water level rising to $175 \mathrm{~m}$ (Ye et al., 2011). The typical seasonal drying-rewetting events lead to remarkable changes in soil physical, chemical and biological properties (Chang et al., 2011). Moreover, the fluctuating shifts in water level and pressure have resulted in extinctions and changes in the population of local plant communities, and frequent human disturbance and exploitation of water and land resources changed the soil structure and hydrological conditions in the reservoir. Consequently, the regional ecosystem has become unstable and fragile (Zhou et al., 2010). Most research on the Three Gorges Reservoir focuses on discussions about its ecosystem function, the reasonable utilization of land resources, and restoration of degenerated ecosystems around the reservoir. However, fundamental research on the soil microbial community in these ecosystems is not well documented. Microbial community structure and function are arguably two of the primary drivers of biogeochemical process in terrestrial ecosystems (Orwin et al., 2006). Previous research conducted on the effects of fluctuating redox in ecosystems on soil microbial community structure have mainly focused on natural ecosystems such as the rhizosphere of wetlands, tropical forest soils, paddy soils, floodplains, and coastal tidal systems (Pett-Ridge and Firestone 2005; Hines 2006; Wilms et al., 2006; Nikolausz et al., 2008; Song et al., 2008; Shamsi, 2012; Moche et al., 2015; Frindte et al., 2016). The fluctuation in redox conditions of these ecosystem is characterized by either randomness or relatively short flooding events, and Eh typically fluctuates across only a narrow range of values. The microbial community composition is in fact largely dependent on the duration of flooding, and also varies with the duration of dry periods (Rinklebe and Langer, 2006; Langer and Rinklebe, 2009). The special water level control systems installed in the Three Gorges reservoir leads to prolonged fluctuations in soil redox conditions, with each state (flood or drought) lasting almost half a year. Fluctuation of water level is therefore a major factor in adjacent ecosystems, providing a unique ecological model in the evaluation of redox-driven changes in soil microbial communities.

To evaluate the dynamics of the soil microbial community response to the prolonged redox fluctuations in the Three Gorges Reservoir, we selected three areas (Wanzhou, Changshou, and Fengdu) at varying elevations along a gradient from downstream to upstream. Our objectives were (i) to determine the effects of prolonged redox disturbances on total PLFA as a proxy for biomass as well as the details of community structure provided by the PLFA profile, and (ii) to identify the impacts of specific environmental factors on the soil microbial community.

\section{Materials and methods}

\subsection{Description of sites and soil sampling}

This study was carried out in the Three Gorges Reservoir area of Chongqing, located in south-west China. This region is typical of south-east subtropical monsoon climates, with a mean temperature of $5.3^{\circ} \mathrm{C}$ in January and $29^{\circ} \mathrm{C}$ in July. Mean annual precipitation is $1100 \mathrm{~mm}$ with $80 \%$ falling between April and October (Ye et al., 2011). The soil is brown purplish soil (Chinese soil classification system), classified as Haplic Cambisols in the World Reference Base (WRB) for soil resources (Shen et al., 2013). Every September, the Three Gorges Reservoir fills with water, with the water level reaching to $175 \mathrm{~m}$ above sea level at the end of October. In the following March, the reservoir starts to drain, with the water level declining to $145 \mathrm{~m}$ above sea level at the end of May. Therefore, the seasonal water level regulation caused the development of two parallel permanent fluctuating belts along the two banks of the reservoir, with about $30 \mathrm{~m}$ water-level fluctuating zone formed. Based on the geographical characteristics of the drawdown zone from upstream to downstream in the Reservoir, three areas which identified as model regions for each fluctuating zone, namely Wanzhou-upstream $\left(30^{\circ} 42^{\prime} 45^{\prime \prime} \mathrm{N}, \quad 108^{\circ} 24^{\prime} 59^{\prime \prime} \mathrm{E}\right), \quad$ Changshou-middle stream $\left(29^{\circ} 47^{\prime} 56^{\prime \prime} \mathrm{N}, \quad 107^{\circ} 4^{\prime} 57^{\prime \prime} \mathrm{E}\right)$, and Fengdu-downstream (295' $\left.14^{\prime \prime} \mathrm{N}, 107^{\circ} 45^{\prime} 15^{\prime \prime} \mathrm{E}\right)$ (Fig. 1).

Soils samples were collected in June 2014 from three sections of elevation from $150 \mathrm{~m}$ to $182 \mathrm{~m}$ representing redox regimes (sites) due to repeated flooding from each of the three different sampling areas (Wanzhou, Changshou and Fengdu). The elevation range of $150 \mathrm{~m}$ to $156 \mathrm{~m}$ was flooded 8 times (8cycle) from 2006 to 2014, the range of $161 \mathrm{~m}$ to $170 \mathrm{~m}$ was flooded 5 times (5-cycle) from 2009 to 2014, and $180 \mathrm{~m}$ to $182 \mathrm{~m}$ was never flooded (0-cycle) (Fig. 2). For Wanzhou, Fengdu, and Changshou, 3 plots were established at each site (with the exception of Fengdu having 4 plots), and were randomly selected along the elevation range from 150 to $182 \mathrm{~m}$. For each sampling plot $(5 \mathrm{~m} \times 5 \mathrm{~m})$, five soil samples from 0 to $20 \mathrm{~cm}$ were collected and well mixed to form 1 composite sample for each of the 3 plots per site. Samples were sealed in plastic bags and transported at $4^{\circ} \mathrm{C}$ to the laboratory. Samples were sieved $(<2 \mathrm{~mm})$ and mixed thoroughly, and a portion of each sample was air-dried for 


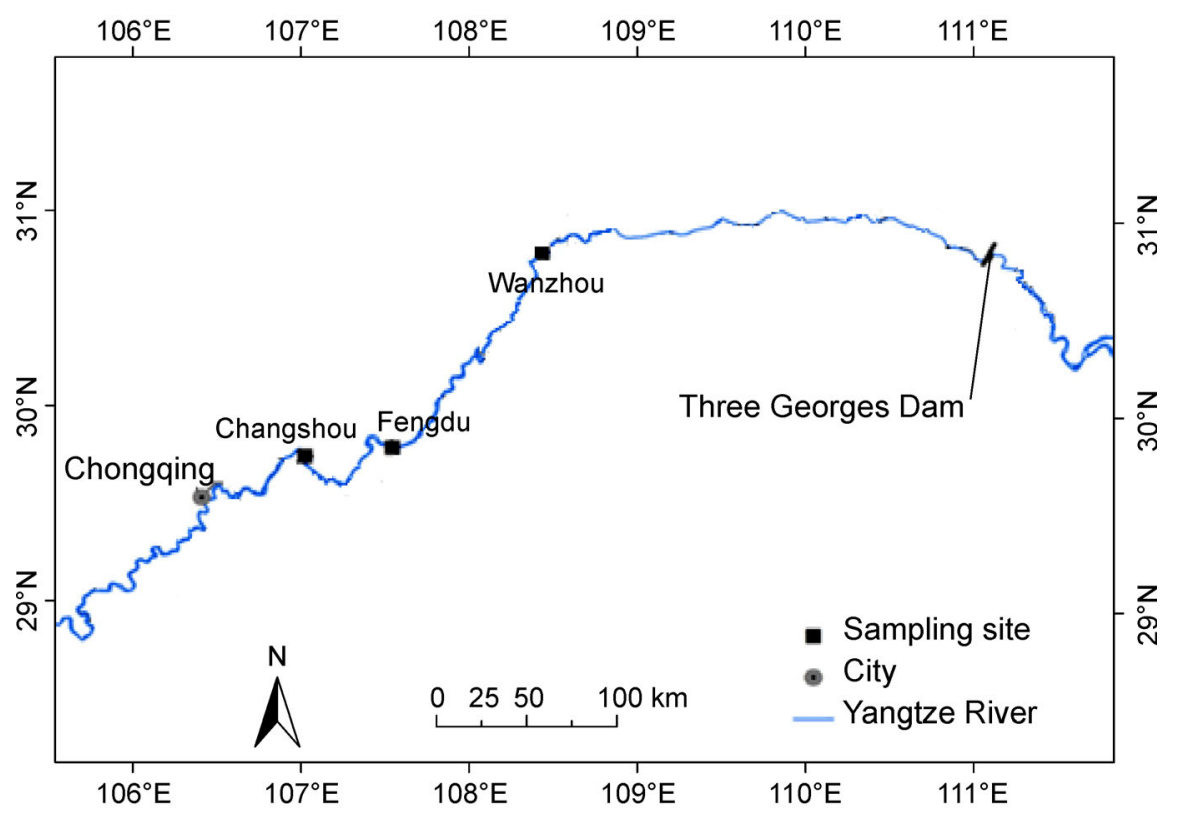

Fig. 1 Study area

soil physiochemical analyses and another portion was stored at $-20^{\circ} \mathrm{C}$ for soil microbial community structure analyses.

2.2 Soil physicochemical and phospholipid fatty acid (PLFA) analyses

Soil moisture was determined by oven-drying fresh soil at $105^{\circ} \mathrm{C}$ to a constant weight. Soil $\mathrm{pH}$ was determined at a ratio of 1:2.5 (soil to water, w/w) using a Mettler Toledo 320-S pH meter (Mettler-Toledo Instruments Co. Ltd., Shanghai, China). Soil total organic carbon (TOC) was determined by acid dichromate wet oxidation (Nelson and Sommers, 1996), total $\mathrm{N}$ was determined by micro-Kjeldahl digestion (Bremner, 1996), and C:N ratios were calculated using these measurements. Soil nitrate content was extracted with $2 \mathrm{M} \mathrm{KCL}$ and determined by a Skalar SAN Plus segmented flow analyzer (Skalar Inc., Breda, The Netherlands).

Phospholipid Fatty Acid (PLFA) analysis was conducted using the method described by Bossio and Scow (1998). Lipids were extracted from $8 \mathrm{~g}$ dry-weight-equivalent fresh soil using a $23 \mathrm{~mL}$ extraction mixture of chloroform: methanol: phosphate buffer $(1: 2: 0.8 \mathrm{v} / \mathrm{v} / \mathrm{v})$, and then the extraction was

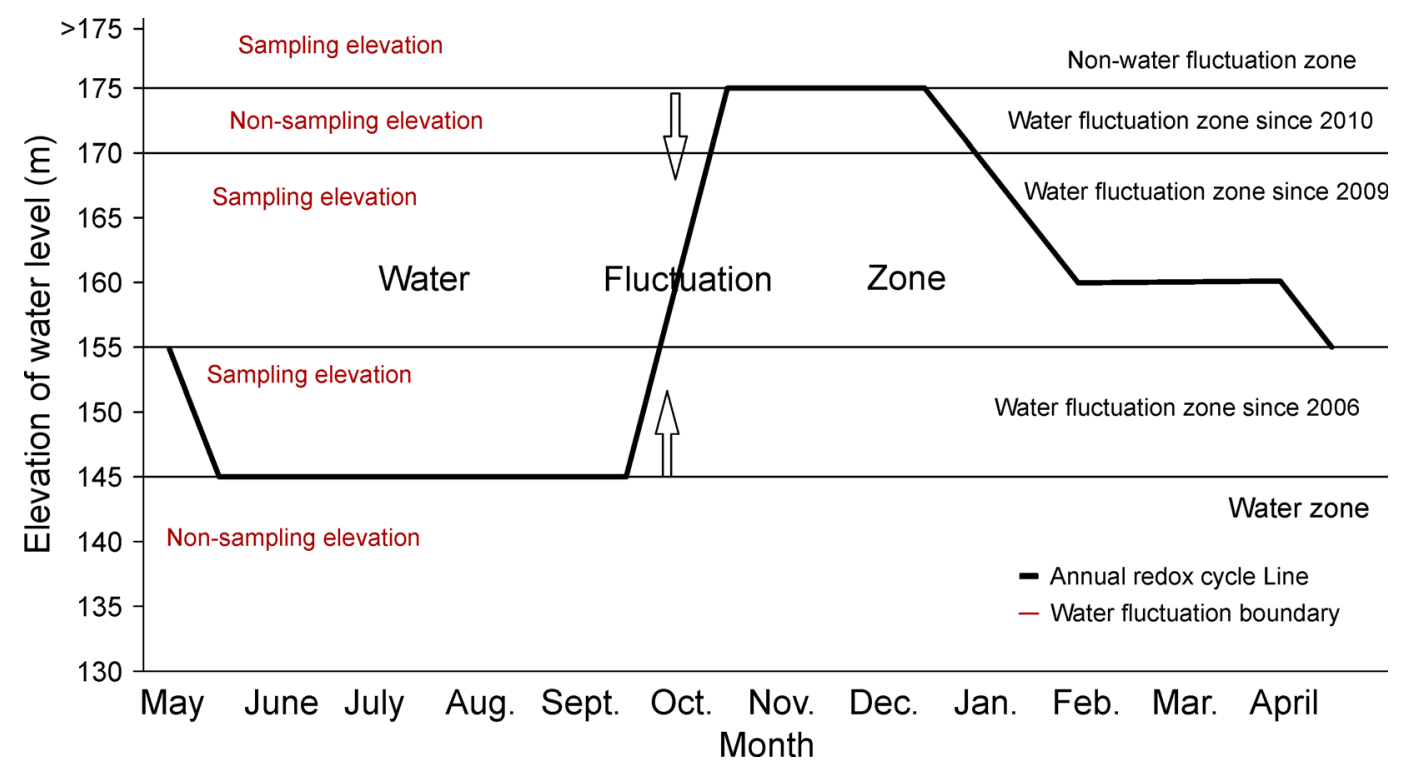

Fig. 2 Annual flooding cycles and sampling elevation (redox regime) in the drawdown zone of the Three Gorges Reservoir region. 
transferred to a separatory funnel. Phospholipids were split into neutral lipids, glycolipids, and phospholipids using solidphase extraction columns by eluting with $\mathrm{CHCl}_{3}$, acetone, and methanol, respectively. Subsequently, phospholipids were subjected to a mild alkaline methanolysis to yield fatty acid methyl esters. Samples were then redissolved in $200 \mathrm{~mL}$ hexane containing the fatty acid 19:0 as an internal standard, and were analyzed using a Hewlett-Packard 6890 Gas Chromatograph equipped with an Ultra 2-methylpolysiloxane column. A $2 \mathrm{~mL}$ injection with a 1:50 split was analyzed at an oven temperature of $260^{\circ} \mathrm{C}$, a flame ionization detector temperature of $300^{\circ} \mathrm{C}$, and a pressure of $10.7 \mathrm{PSI}$ at a constant flow rate of $0.4 \mathrm{~mL} \cdot \mathrm{min}^{-1}$. Peaks were identified using bacterial fatty acid standards and MIDI peak identification software (MIDI, Inc., Newark, DE). General bacteria were identified by the following straight chain, terminal-branched saturated and cyclopropyl PLFAs: 12:0, 14:0, i14:0, a15:0, i15:0, i15:1G, 16:0, i16:0, a17:0, i17:0, cy17:0, 20:0 (Vestal and White, 1989). The terminal-branched saturated PLFAs $\mathrm{i} 14: 0$, a15:0, i15:0, i16:0, a17:0 and i17:0 were used as markers for Gram-positive bacteria (lbekwe and Kennedy, 1998; Cao et al., 2010). The linear monounsaturated and cyclopropyl PLFAs: 16:1w9c, 16:1w5c, 17:1w8c, 18:1w5c, $18: 1 w 9 c$, cy17:0 were markers of Gram-negative bacteria (Bossio et al., 2006). Actinomycetes were represented by the methylic, mid-chain-branched saturated PLFAs 10Me17:0, and 10Me18:0 (Fernandes et al., 2013). Straight and terminal chain branched saturated PLFAs 16:0 and i17:0 were indicative of $\mathrm{SO}_{4}$-reducing bacteria (SRB) (Findlay and Dobbs, 1993). The linear monounsaturated PLFAs 16:1w5c and $18: 1 \mathrm{w} 9 \mathrm{c}$ were indicative of methanotrophs and fungi (Sundh et al., 2000; Bååth and Anderson, 2003). The monounsaturated PLFA 18:1w9c was associated with aerobic bacteria (Guckert et al., 1985; Bossio et al., 1998) and anaerobic bacteria were associated with the terminal branched saturated PLFAs a17:0 and i16:0 (Findlay et al., 1990; Bossio et al., 1998). PLFA 20:4w6c (6.9.12.15) was an indicator for protozoa (van Aarle and Olsson, 2003; Fernandes et al., 2013). The relative abundance of individual fatty acids was expressed as the proportion ( $\mathrm{mol} \%$ ) relative to the sum of all fatty acids, and microbial biomass was calculated as the sum of the individual PLFAs $\left(\mathrm{nmol} \cdot \mathrm{g}^{-1}\right.$ soil). The prefixes 'i', 'a', and 'Me' indicate iso, anteiso, and mid-chain methyl branching, and the prefix 'cy' refers to cyclopropyl rings (Navarrete et al., 2000).

A ratio of fungi to general bacterial PLFAs (F:B) was analyzed, and a ratio of the sum of linear monounsaturated PLFAs to the sum of branched chain saturated PLFAs (Mono/ Branch), i.e., $(14: 1 w 5 c, 16: 1 w 5 c, 16: 1 w 9 c, 16: 1 w 11 c$, 17:1w8c, 18:1w5c, 18:1w9c, 20:1w9c) / (i12:0 30H, i14:0, a15:0, i15:0, i15:1G, i16:0, i16:1G, 16:1 2OH, a17:0, i17:0, $\mathrm{i} 17: 03 \mathrm{OH}$ ) was used to indicate the relative ratio of aerobic to anaerobic microorganisms (Bossio et al., 2006; Cao et al., 2010). The ratio of Gram-positive bacteria to Gram-negative bacteria PLFAs $\left(\mathrm{G}^{+} / \mathrm{G}^{-}\right)$and the ratio of actinomycete to bacterial PLFAs (A/B) were also determined.

\subsection{Statistical analysis}

Analysis of variance and Tukey pairwise comparison tests were used to test for significant differences between sites $(p<0.05)$, which were performed with SPSS 13.0. Principal component analysis (PCA) and redundancy analysis (RDA), conducted on Canoco 4.5, were used to compare microbial community structure across all samples sites and determine the influence of environmental factors on soil microbial diversity.

\section{Results}

\subsection{Selected soil properties}

The repeated flooding in the fluctuating zone significantly $(p<0.05)$ affected the soil physiochemical properties of the studied soils (Table 1). Soil $\mathrm{pH}$ in the 8-cycle plots was significantly $(p<0.05)$ higher than that in the 5-cycle and 0 cycle at all three sites. Moreover, the other selected soil properties including $\mathrm{C}: \mathrm{N}$ ratio, $\mathrm{NO}_{3}{ }^{-}, \mathrm{TN}$, and $\mathrm{TOC}$ also showed the similar variable trends to soil $\mathrm{pH}$, that is, the concentration of these soil properties generally increased with increases in flooding duration (Table 1).

\subsection{Soil microbial functional group composition}

A total of 31 different PLFA markers were identified in the redox regimes across Changshou, Wanzhou and Fengdu. The PCA analysis of Fig. 3 revealed three separate clusters of redox regimes and PLFA markers of the drawdown zone and the never flooded zone in the Three Gorges Reservoir region. The first cluster of redox regimes, including the 0-cycle samples from Changshou, Wanzhou and Fengdu, was positively associated to the PC1 axis and mainly dominated by linear monounsaturated PLFAs, mid-branched chain PLFAs, and cyclopropyl and polyunsaturated PLFAs. The second cluster was negatively associated with both PC1 and PC2, including 8-cycle from all the three areas, and 5-cycle from Changzhou, and was dominated by straight chain PLFAs. The third cluster was positively associated to PC2 axis, including 5-cycle from Changshou and Wanzhou, and was dominated mostly by terminal and hydroxyl branched chain PLFAs. Both PCs accounted for $64 \%$ of the variance.

Moreover, the PCA analysis of PLFA markers in Fig. 3 (B) showed that straight chain saturated PLFAs, terminal and hydroxyl branched chain PLFAs, monounsaturated chains (16:1w11c, 14:1w5c), and cyclopropyl unsaturated chains (cy17:0) were dominant in the 8-cycle and 5-cycle plots of the drawdown zone compared to the 0 -cycle of the native plant community across Changshou, Fengdu and Wanzhou. In contrast, monounsaturated chain PLFAs, terminal branched chain PLFAs (i15:1G, i16:1G), mid-branched chain PLFAs, a cyclopropyl unsaturated chain PLFA (cy19:0w8c), and polyunsaturated chain PLFAs were dominant in the 0-cycle plots of the native plant zone compared to the 8-cycle and 5-cycle plots. 
Table 1 The selected soil properties of the redox regimes from three study areas in the Three Gorges Reservoir Region

\begin{tabular}{|c|c|c|c|c|c|c|c|}
\hline Area & Altitude & Site & $\mathrm{pH}$ & TOC $\left(\mathrm{g} \cdot \mathrm{kg}^{-1}\right.$ soil) & C:N ratio & $\mathrm{TN}\left(\mathrm{g} \cdot \mathrm{kg}^{-1}\right.$ soil $)$ & $\mathrm{NO}_{3}^{-}\left(\mathrm{mg} \cdot \mathrm{kg}^{-1}\right.$ soil $)$ \\
\hline \multirow[t]{3}{*}{ Changshou } & $156 m$ & 8-cycle & $8.20 \pm 0.00 a$ & $7.49 \pm 0.94 a$ & $10.57 \pm 1.80 \mathrm{a}$ & $0.71 \pm 0.05 a$ & $63.50 \pm 3.06 a$ \\
\hline & $163 m$ & 5-cycle & $8.27 \pm 0.06 a$ & $4.35 \pm 1.05 b$ & $7.77 \pm 2.59 a$ & $0.56 \pm 0.05 c$ & $59.99 \pm 7.69 a$ \\
\hline & $181 \mathrm{~m}$ & 0-cycle & $6.70 \pm 0.72 b$ & $4.47 \pm 0.47 b$ & $7.37 \pm 0.14 b$ & $0.61 \pm 0.07 b$ & $61.15 \pm 6.68 a$ \\
\hline \multirow[t]{3}{*}{ Fengdu } & $151 \mathrm{~m}$ & 8-cycle & $8.13 \pm 0.12 a$ & $8.39 \pm 1.49 a$ & $11.00 \pm 0.53 a$ & $0.76 \pm 0.10 \mathrm{a}$ & $63.21 \pm 7.69 a$ \\
\hline & $164 \mathrm{~m}$ & 5-cycle & $7.70 \pm 0.17 \mathrm{~b}$ & $6.77 \pm 1.57 \mathrm{~b}$ & $10.63 \pm 2.25 a$ & $0.64 \pm 0.06 \mathrm{~b}$ & $55.86 \pm 4.44 b$ \\
\hline & $180 \mathrm{~m}$ & 0 -cycle & $7.97 \pm 0.06 b$ & $6.16 \pm 1.03 b$ & $7.96 \pm 0.74 b$ & $0.77 \pm 0.08 a$ & $58.8 \pm 5.09 b$ \\
\hline \multirow[t]{7}{*}{ Wanzhou } & $153 m$ & 8-cycle & $8.10 \pm 0.10 a$ & $10.60 \pm 2.63 b$ & $11.47 \pm 2.43 b$ & $0.92 \pm 0.04 a$ & $87.61 \pm 1.02 a$ \\
\hline & $170 \mathrm{~m}$ & 5-cycle & $6.93 \pm 0.57 b$ & $12.71 \pm 0.19 a$ & $13.37 \pm 1.51 b$ & $0.95 \pm 0.12 a$ & $75.26 \pm 7.13 b$ \\
\hline & $182 m$ & 0-cycle & $7.00 \pm 0.42 b$ & $11.81 \pm 0.58 b$ & $21.64 \pm 4.96 a$ & $0.55 \pm 0.13 b$ & $68.80 \pm 9.96 b$ \\
\hline & repeated & & & & & & \\
\hline & $A$ & & ns & ** & ** & ns & ns \\
\hline & $\mathrm{F}$ & & $* *$ & * & ns & ns & * \\
\hline & $A \times F$ & & * & * & * & * & * \\
\hline
\end{tabular}

Values are means \pm standard errors for the sampling plots: 8-cycle plot $(n=3), 5$-cycle plot $(n=3), 0$-cycle plot $(n=3)$. TOC, C:N and TN refer to soil total organic carbon, the ratio of soil organic carbon to soil total nitrogen and soil total nitrogen respectively. Numbers in a rank with different letters indicate a significant difference (Turkey's Test, $P<0.05$ ). A, Area; F, Flooding cycle. $\mathrm{n}$, indicates no significance; *, indicates a significance at $p<0.05 ;{ }^{* *}$, indicates a significance at $p<0.01$.

Despite the variation in soil properties from different locations, the patterns in the shifts of functional groups due to the recurring redox disturbances were the same across Changshou, Wanzhou and Fengdu (Fig. 4). For instance, the straight chain saturated PLFAs at Changshou showed increases (relative to the 0 -cycle site) of $13.6 \%$ and $4.5 \%$ at the 8-cycle and 5-cycle plots, respectively. These increases were $12.1 \%$ and $11.5 \%$ at the 8 -cycle and 5 -cycle plots at Fengdu, and $25.5 \%$ and $12.4 \%$ at Wanzhou, respectively. The branch chain saturated PLFAs were $18.6 \%$ (Changshou), $25.4 \%$ (Fengdu) and 27.6\% (Wanzhou) higher at the 5-cycle plots and $8.7 \%$ (Changshou), $5.7 \%$ (Fengdu) and $10.8 \%$ (Wanzhou) higher at the 8-cycle plots compared to the 0-cycle plots. The cyclopropyl PLFAs experienced a 18.3\% (Changshou), $14.5 \%$ (Fengdu) and $20.6 \%$ (Wanzhou) increase at the 8-cycle plots and 66.8\% (Changshou), 36.6\% (Fengdu) and $29.6 \%$ (Wanzhou) increase at the 5-cycle plots compared to the 0 -cycle plots. The linear monounsaturated PLFAs decreased by $41.8 \%$ (Changshou), $40.6 \%$ (Fengdu) and $55.8 \%$ (Wanzhou) at the 8-cycle plots and $22.6 \%$ (Changshou), $17.4 \%$ (Fengdu) and $27.5 \%$ (Wanzhou) at the 5-cycle plots compared to the 0-cycle plots (Fig. 4).

\subsection{Redox cycle effects on microbial community structure}

Compared to the 0 -cycle plots, the total amount of PLFAs significantly $(p<0.05)$ decreased in the 8 -cycle plots, followed by the 5-cycle plots (Fig. 5). Gram-positive bacteria, sulfatereducing bacteria, and anaerobic bacteria were predominant in the 8-cycle and 5-cycle plots, whereas fungi, Gramnegative bacteria, actinomycetes, methanotrophs, aerobic bacteria, and protozoa were enriched in the 0-cycle plots (Fig. 5). Significant statistical variation existed between the drawdown zone (8-cycle and 5-cycle plots) and the native soils $(0$-cycle plots) $(p<0.002)$, which also explained the survival disadvantage for certain microorganisms such as fungi, protozoa, Gram-negative bacteria, actinomycetes, and aerobic bacteria in the drawdown zone. Among all the groups, protozoa were proportionally low and were completely absent from the 8-cycle plots of the drawdown zone at all the studied areas.

\subsection{Compositional and physiological indicators}

Fungi to bacteria ratio ( $\mathrm{F}: \mathrm{B}$ ratio), actinomycete to bacteria ratio $(A: B$ ratio), and aerobic bacteria to anaerobic bacteria ratio (Aero:Anae ratio) were proportionally higher at the 0 cycle plots compared to the 8- and 5-cycle plots of the drawdown zone at Changshou, Wanzhou and Fengdu (Fig. 6). In contrast, the Gram positive to Gram negative bacteria ratio $\left(\mathrm{G}^{+}: \mathrm{G}^{-}\right.$ratio) was significantly $(p<0.05)$ higher at the 8 and 5 cycle plots of the drawdown zone compared to the 0 -cycle plots at Changshou, Wanzhou and Fengdu. The stress indicator represented by the mono unsaturated PLFAs to branched chain PLFAs ratio (Mono: Branch) was proportionally more abundant at the 0-cycle plots compared to the 8 and 5 cycle plots of the drawdown zone at Changshou, Wanzhou and Fengdu (Fig. 6). The results show that prolonged redox disturbances had a negative influence on the $F: B$ ratio and $A: B$ ratio indicators but enhanced the $G^{+}: G^{-}$ ratio in the drawdown zones. Additionally, prolonged redox disturbances had a devastating effect on the Mono: Branch physiological indicator, which reflects the disadvantage in the drawdown zone to organisms requiring oxygen.

\subsection{Microbial PLFA characteristics and selected soil properties}

RDA was performed to study the effect of environmental variables on abundance of microbial phyla (Fig. 7). Both PCs 

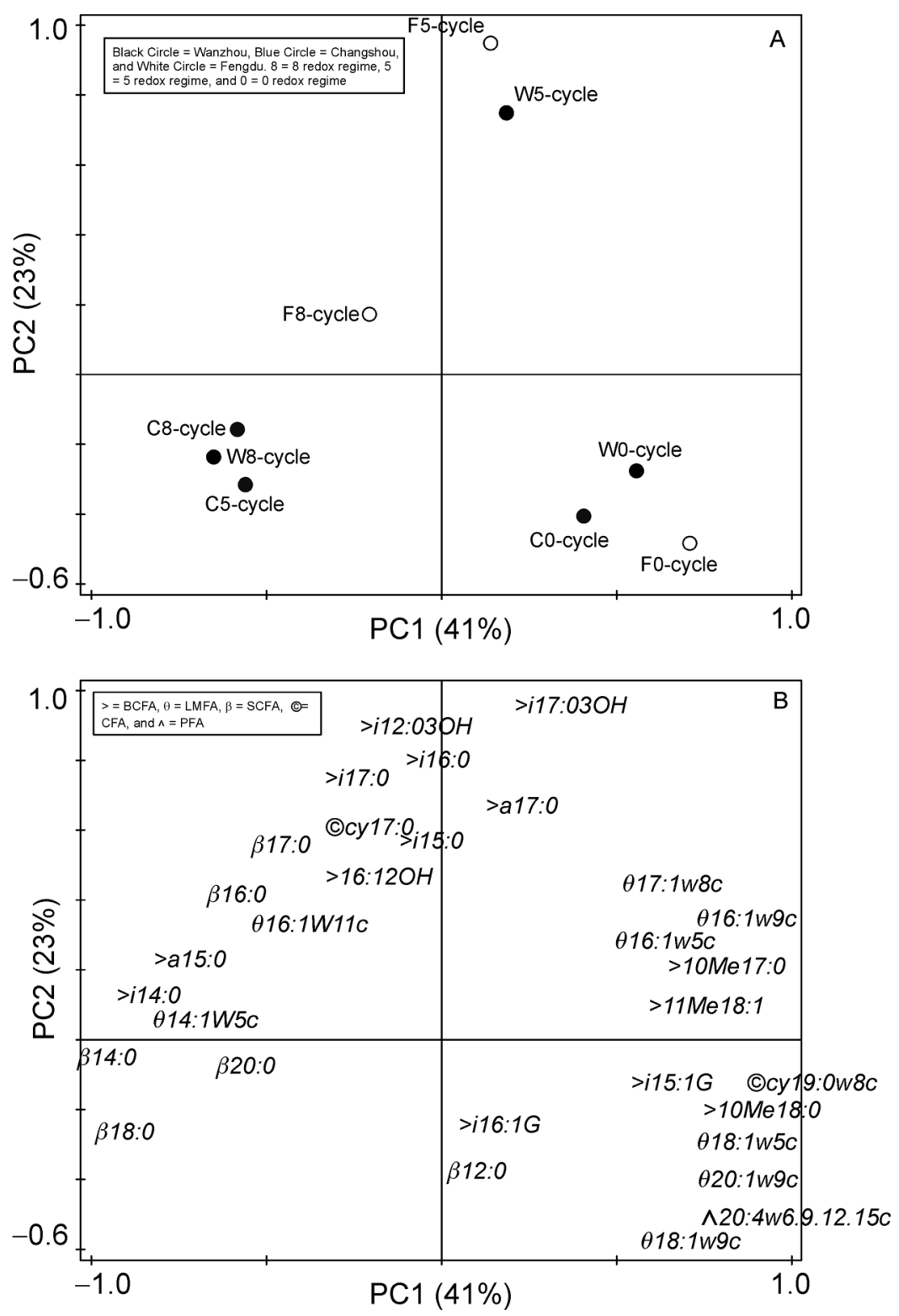

Fig. 3 Principal component analysis (PCA) of phospholipid fatty acid (PLFA) data in the redox regimes of Changshou, Wanzhou and Fengdu of the Three Gorges Reservoir region (A) and loading scores for individual PLFAs (B).

accounted for $93 \%$ of the total variance, with the first function explaining $79 \%$ and the second explaining $14 \%$ of the variance, respectively. The positive loading of TOC and C:N ratio on the $\mathrm{PC} 1$ axis indicated a positive correlation with protozoa, Gram negative bacteria, fungi, aerobic bacteria, actinomycetes and methanotrophs, but a negative correlation with bacteria, Gram positive bacteria, sulfate-reducing bacteria, and anaerobic bacteria. Furthermore, the negative loading of $\mathrm{pH}, \mathrm{TN}$ and $\mathrm{NO}_{3}{ }^{-}$on the $\mathrm{PC} 2$ axis reflects a positive correction with general bacteria, Gram positive bacteria, sulfur-reducing bacteria and anaerobic bacteria, but a negative correlation with protozoa, Gram negative bacteria, fungi, aerobic bacteria, actinomycetes and methanotrophs.

\section{Discussion}

4.1 Redox disturbance effects on soil PLFA functional groups

Studies have shown that as soil redox potential changes, the dominance of specific functional groups shifts (Picek et al., 2000). In the study, a comparative analysis of various redox regimes in the drawdown zone and native soils showed significant $(p<0.05)$ increases in the relative abundance of certain straight chain saturated and cyclopropyl PLFAs, terminal and mid-branched PLFAs, and a consistent decrease in most linear monounsaturated and polyunsaturated PLFAs at the 8-cycle and 5-cycle plots of the drawdown zone (Fig. 4). Actually, winter flooding has been shown to increase the 

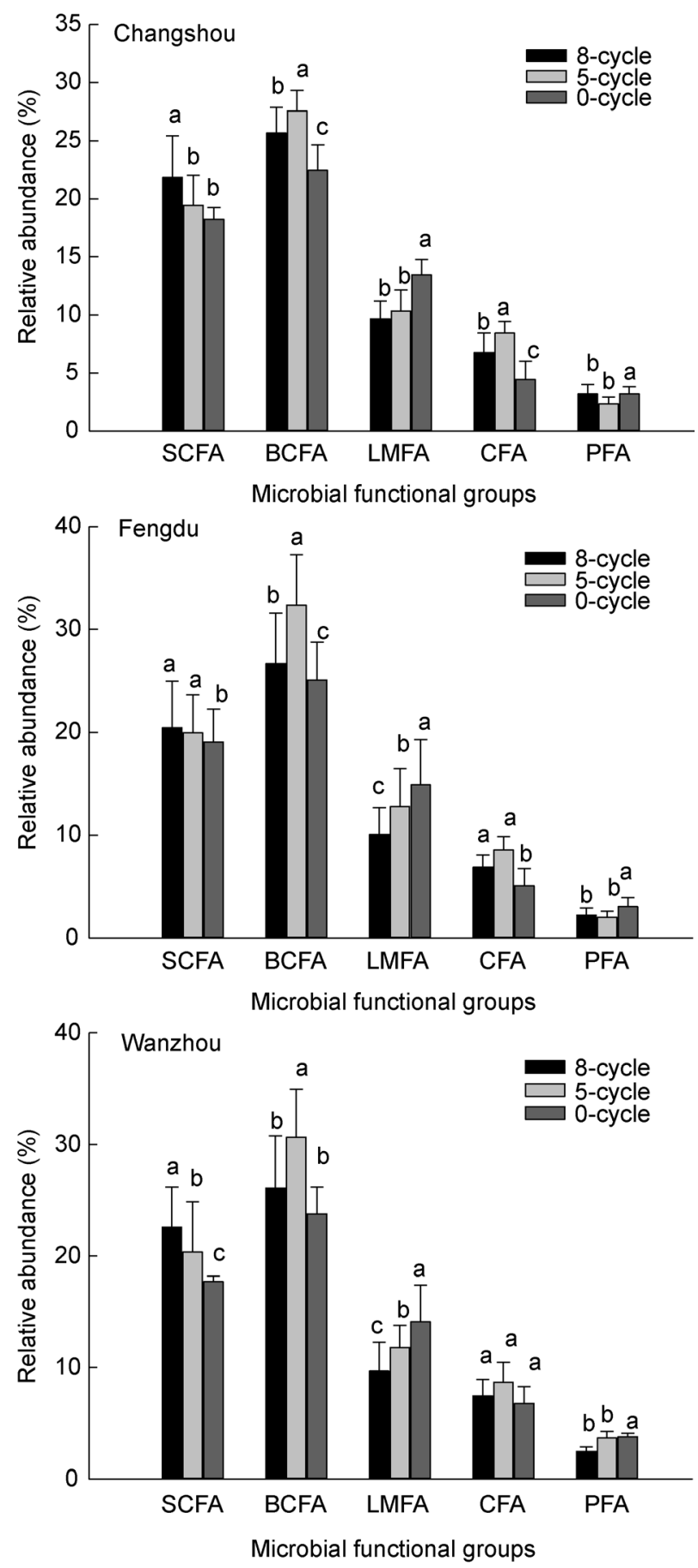

Fig. 4 Distribution of functional groups in the redox regimes in Changshou, Wanzhou and Fengdu of the Three Gorges Reservoir Region. The graphs indicate 5 sub-groups of PLFA biomarkers: SCFA = straight chain saturated fatty acids, BCFA = branched chain saturated fatty acids, CFA = cyclopropyl fatty acids, LMFA = linear monounsaturated fatty acids, and PFA = polyunsaturated fatty acids. 8-cycle $=$ flooded 8 times with elevation of 150-156 m, 5-cycle $=$ flooded 5 times with elevation of $161-170 \mathrm{~m}, 0$-cycle $=$ never flooded with elevation of 180 $182 \mathrm{~m}$. The error bars represented standard error $(n=3)$, values with different letters indicate a significant difference at $p<0.05$. relative abundance of certain straight chain saturated PLFAs and branched PLFAs, and decrease linear monounsaturated PLFAs (Bossio and Scow, 1998). Linear monounsaturated PLFAs in rice paddies were sensitive to flooding, which suggested that these fatty acids are indicators of aerobic conditions (Langer and Rinklebe, 2009). This explains the relative decline of certain straight chain saturated PLFAs, cyclopropyl PLFAs, terminal and mid-branched PLFAs, most linear monounsaturated PLFAs, and the conspicuous disappearance of polyunsaturated PLFAs at the 8-cycle plots of the drawdown zone (Fig. 4). Cyclopropyl PLFAs are common in some Gram-negative strains, as well as in some anaerobic strains of Gram-positive bacteria (Bai et al., 2000). In our study, cy17:0 but not cy19:0w8c, was insensitive to prolonged redox disturbance in the drawdown zone.

\subsection{Shifts in microbial community structure due to redox changes}

Based on PCA analysis of the PLFA data, the distinct three cluster grouping of microbial communities according to the recurrence of dry down-rewetting cycles $(0,5$, or 8$)$ indicates the dominant influence of flooding in shaping soil microbial community structures around the reservoir (Fig. 3). In our case, prolonged redox disturbances significantly $(p<0.05)$ reduced total soil PLFAs, which significantly decreased with increased flooding recurrence (Fig. 5). Obligate anaerobes may quickly decline as the environment is forced to become wholly aerobic due to the effects of $\mathrm{O}_{2}$ toxicity (Imlay, 2002), while obligate aerobes may be inactivated or starved as $\mathrm{O}_{2}$ becomes limiting (Fenchel and Finlay, 1995). Therefore, alternating oxic and anoxic conditions may act as an environmental stressor for certain soil microbial groups. Moreover, the specific perturbations of fluctuations in soil redox conditions to soil microbial community structure largely depend on flood duration and the time since the soil was last flooded (Rinklebe and Langer, 2006; Langer and Rinklebe, 2009). As for the high-amplitude fluctuating redox regimes, it seems that rapidly fluctuating redox regimes of humid tropical forest soils act as a strong selective force on the phylogenetic and physiological compositions of soil microorganisms and may promote metabolic plasticity or redox tolerance mechanisms (Pett-Ridge and Firestone, 2005). In our case, the duration of floods and dry periods in the fluctuating zone of the Three Gorge Reservoir is relatively long (almost 6 months). At each relatively stable period (flood or dry), soils in the fluctuating zone are dominated by two types of microbial groups adapting to the present soil redox conditions. However, environmental fluctuations bring a huge disturbance to the previous, relatively stable microbial habitats, and the cycling between the two states prevents the community from stabilizing with a predominantly aerobic or anaerobic population. Additionally, alternate drying and wetting accelerates the decomposition of soil organic matter, which is not conducive to maintaining a high microbial biomass level (Or et al., 2007; Wu. 1994). Therefore, soils experiencing prolonged fluctuating redox conditions may be disadvantageous for maintaining 

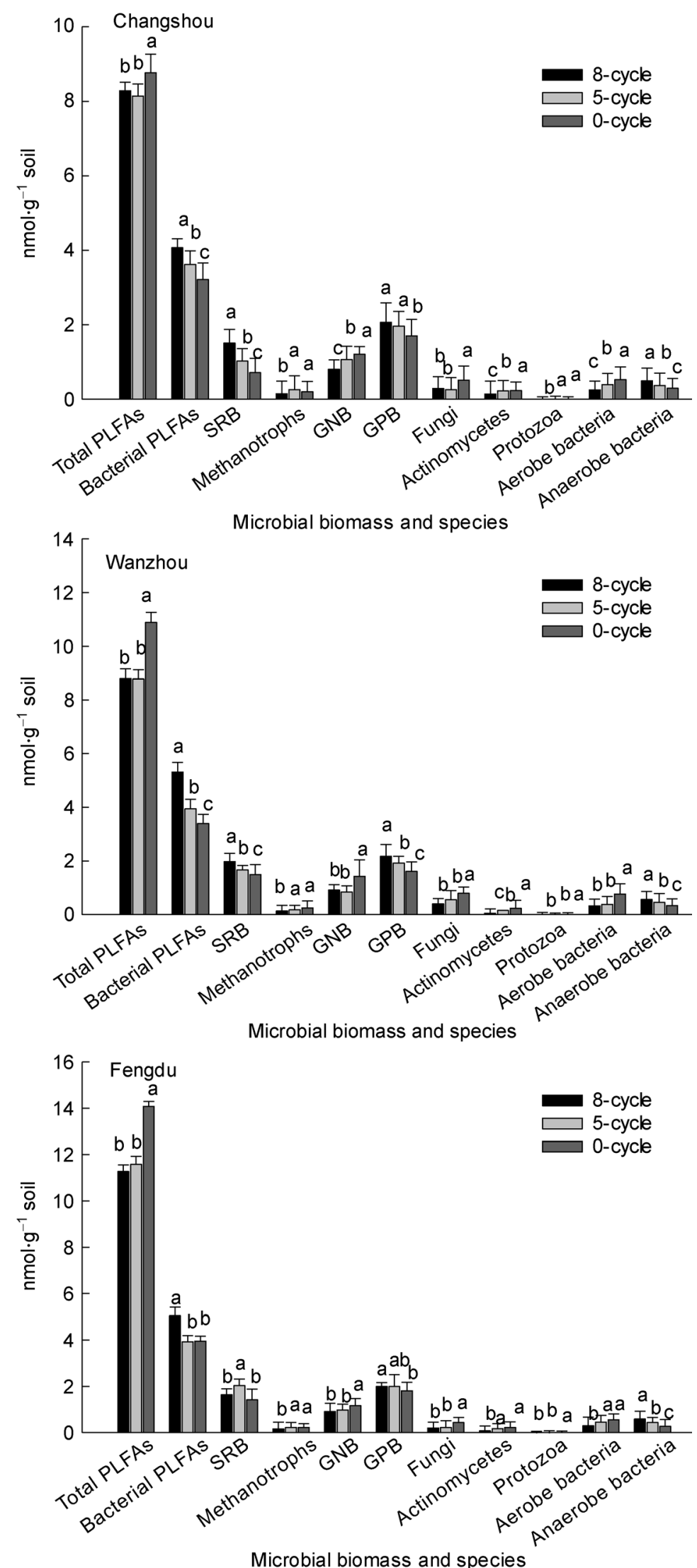

Fig. 5 The microbial biomass and species for the redox regimes in Changshou, Wanzhou and Fengdu of the Three Gorges Reservoir Region. SRB = sulfate-reducing bacteria, GNB = Gram-negative bacteria, GPB = Gram-positive bacteria. 8-cycle = flooded 8 times with elevation of 150-156 m, 5-cycle = flooded 5 times with elevation of 161-170 m, 0-cycle = never flooded with elevation of 180-182 $\mathrm{m}$. The error bars represented standard error $(n=3)$, values with different letters indicate a significant difference at $p<0.05$. 

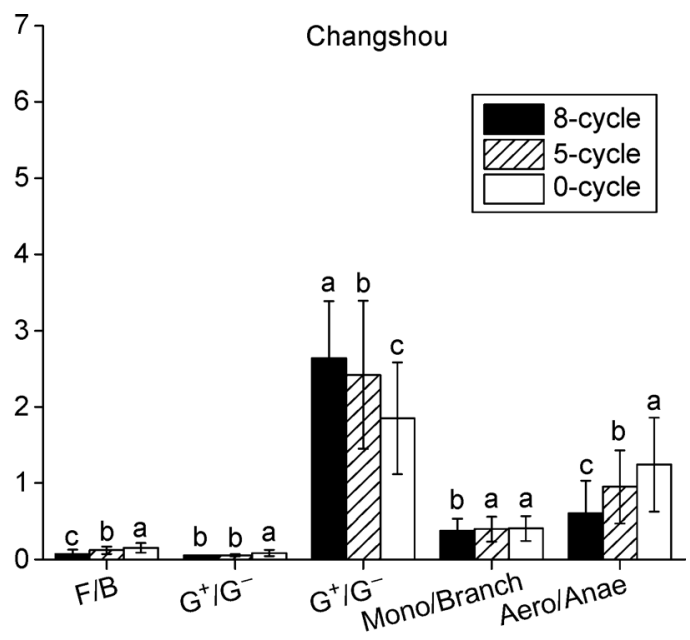

Microbial indicator

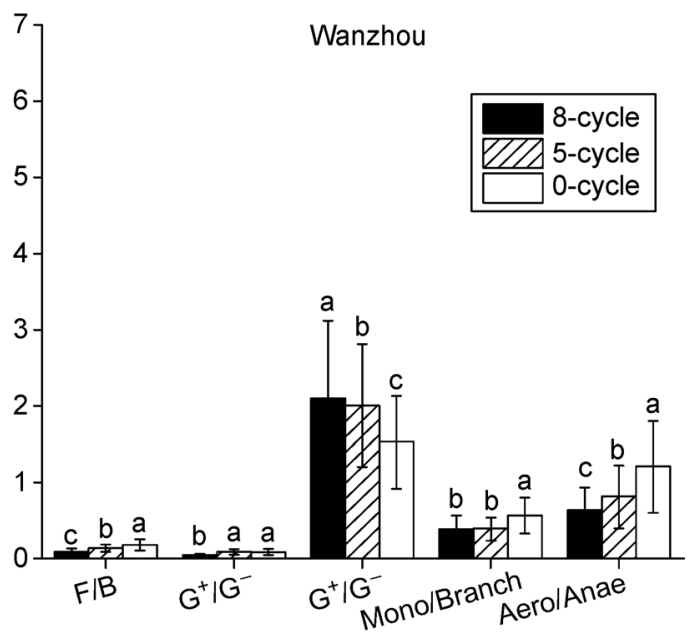

Microbial indicator

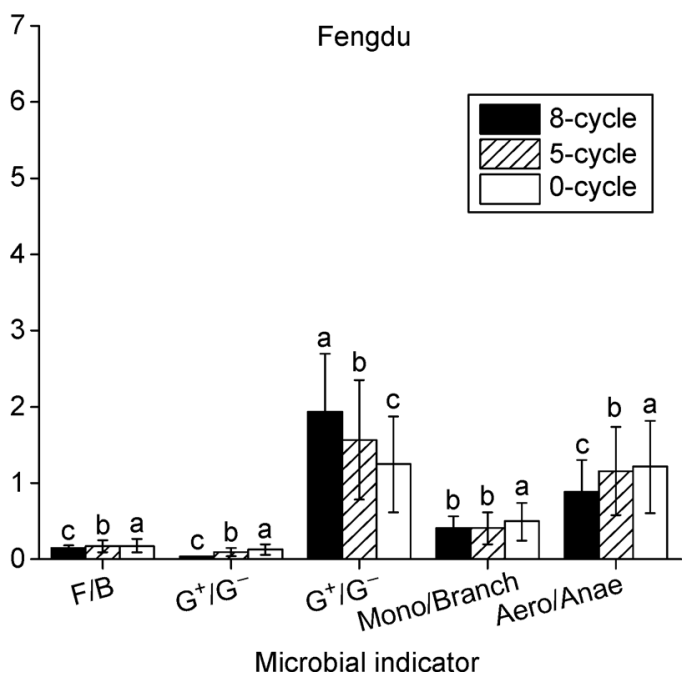

Fig. 6 The PLFA-based microbial compositional and physiological characteristics for the redox regimes in Changshou, Wanzhou and Fengdu of the Three Gorges Reservoir region. The PLFA-based microbial community indicators, including $F / B=$ fungi to bacteria ratio, $A / B=$ actinomycetes to bacteria ratio, and $\mathrm{G}^{+} / \mathrm{G}^{-}=\mathrm{Gram}$-negative bacteria to Gram-negative ratio. Mono/Branch (stress characteristic) $=$ linear monounsaturated PLFA to branched chain saturated PLFA. 8-cycle $=$ flooded 8 times with elevation of 150-156 m, 5-cycle = flooded 5 times with elevation of 161-170 m, 0-cycle = never flooded with elevation of 180-182 $\mathrm{m}$. The error bars represented standard error $(n=3)$, values with different letters indicate a significant difference at $p<0.05$. 


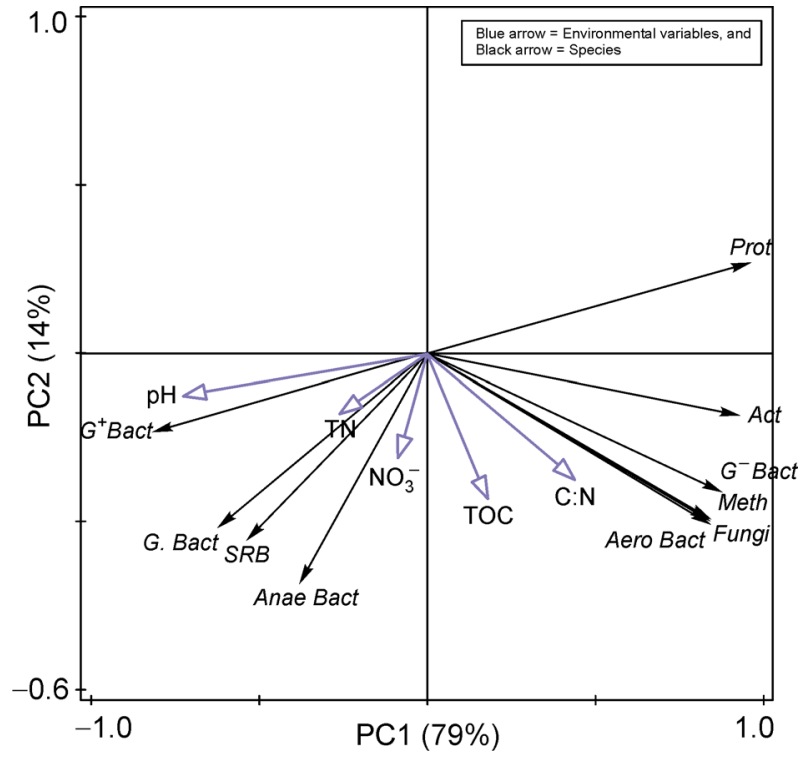

Fig. 7 Redundancy analysis (RDA) illustrating the relationship between microbial abundant phyla and environmental variables. Soil properties $(\mathrm{TOC}=$ total organic carbon, $\mathrm{C}: \mathrm{N}=$ carbon to nitrogen ratio, $\mathrm{TN}=$ soil total nitrogen, $\mathrm{NO}_{3}{ }^{-}=$soil nitrate). PLFA microbial indicators $(G$. Bact $=$ general bacteria, $S R B=$ sulfatereducing bacteria, Meth $=$ methanotrophs, $\mathrm{G}^{-}$Bact $=$Gram negative bacteria, $\mathrm{G}^{+}$Bact $=\mathrm{Gram}$-positive bacteria, fungi, $\mathrm{Act}=$ actinomycetes, Prot $=$ protozoa, Aero Bact $=$ aerobic bacteria, Anae Bact $=$ anaerobic bacteria).

higher microbial biomass.

The microbial PLFA profile in the fluctuating zone (5- and 8cycle plots) was dominated by Gram-positive bacteria, sulfate-reducing bacteria and anaerobic bacteria, and the quantities of those microbial PLFAs in the fluctuating zone increased with increases in numbers of drying-rewetting cycles (Fig. 5). The abundance of fungi, Gram-negative bacteria, actinomycetes, methanotrophs and aerobic bacteria decreased under fluctuating redox conditions (5- and 8-cycle plots) in comparison with the drier 0-cycle plots, which is consistent with previous studies that these microorganisms are less prevalent in soils with fluctuating water levels (Bossio and Scow, 1998; Mentzer et al., 2006; Langer and Rinklebe., 2009; Balasooriya et al., 2013). Indeed, the fast-growing Gram-negative bacteria, which utilize a variety of carbon sources under well aerated conditions, were more abundant in aerobic plots than in plots with a lower oxygen concentration (Bellinger et al., 2012). The duration of flooding events would have a negative effect on Gram-negative bacteria, while the slower growing Gram-positive bacteria may have a greater stress tolerance to fluctuations in water content because of their different physiology and ability to form spores (Mentzer et al., 2006; $\mathrm{Li}$ et al., 2015). Hence, the $\mathrm{G}^{+} / \mathrm{G}^{-}$ratio in the fluctuating zone was higher in comparison with the drier plots (0-cycle plots) (Fig. 6). In our case, the frequent reversal of oxic-anoxic conditions caused by the water level control system would lead to high stress on the fungi, as fungi were more abundant in the drier zone (0-cycle plots) than in the fluctuating zone (5- and 8-cycle plots) (Fig. 5). The negative effect of flooding on fungal biomass has been reported previously (Drenovsky et al., 2004; Guenet et al., 2012). It is noteworthy that the protozoa biomass showed low abundance in the fluctuating zone. Previous reports have found that the dominance of Gram-positive bacteria in reduced soil environments was often accompanied by a low protozoa population (Sinclair and Ghiorse, 1989; England et al., 1993). Prolonged fluctuating redox environments may be inappropriate for strictly aerobic protozoans, which were detected only in the oxic soils.

\subsection{Microbial characteristics and selected soil properties}

Most studies have shown no relationships between PLFA community structure and soil TC and TN (Clegg et al., 2003). PLFA evenness measures are often positively correlated to $\mathrm{TC}$ and C: $\mathrm{N}$ ratio, but PLFA patterns due to mineral $\mathrm{N}$ availability are inconsistent (Bardgett et al., 2001). In the present study, total PLFA, F/B, A/B and mono/branch ratios were negatively correlated with soil $\mathrm{pH}, \mathrm{TOC}$, and $\mathrm{TN}$, which suggests that these soil properties, as the constraint on soil microbial characteristics in the drawdown zone, were restricted by other environmental variables. Therefore, disturbances, such as repeated flooding in the drawdown zone, created redox gradients, and stimulated changes in the microbial community structure at different redox regimes that gave rise to a new, significantly different, microbial community.

\section{Conclusion}

The prolonged and recurring redox disturbances in the drawdown zone of the Three Gorges Reservoir region significantly altered microbial community composition and diversity. The soil microbial community was sensitive to changes in redox potential created by a disturbance such as repeated flooding and drying cycles. The shift in microbial community structure in the drawdown zone due to the prolonged redox disturbance altered microbial functional groups since the microbial community that adapted to such rapidly fluctuating redox conditions was distinct from the original community. The drawdown zone seems to be disadvantageous for fungi, protozoa, gram-negative bacteria, actinomycetes, and aerobic bacteria. There is a need for further studies to validate the exact impact of the shifts in microbial community structure on processes related to microbial activity, e.g., nutrient cycling, which will enhance understanding of soil microbial community metabolic processes in the drawdown zone of the Three Gorges Reservoir region.

\section{Acknowledgments}

This research was financed by the National Natural Science Foundation of China (Nos. 41271267, 41301315). 


\section{References}

Bååth, E., Anderson, T.H., 2003. Comparison of soil fungal/bacterial ratios in a $\mathrm{pH}$ gradient using physiological and PLFA-based techniques. Soil Biology \& Biochemistry 35, 955-963.

Bai, Q., Gattinger, A., Zelles, L., 2000. Characterization of microbial consortia in paddy rice soil by phospholipid analysis. Microbial Ecology 39, 273-281.

Balasooriya, W.K., Huygens, D., Denef, K., Roobroeck, D., Verhoest, N.E.C., Boeckx, P., 2013. Temporal variation of rhizodeposit-C assimilating microbial communities in a natural wetland. Biology and Fertility of Soils 49, 333-341.

Bardgett, R.D., Jones, A.C., Jones, D.L., Kemmitt, S.J., Cook, R., Hobbs, P.J., 2001. Soil microbial community patterns related to the history and intensity of grazing in sub-montane ecosystems. Soil Biology \& Biochemistry 33, 1653-1664.

Binnerup, S.J., Jensen, K., Revsbech, N.P., Jensen, M.H., Sørensen, J., 1992. Denitrification, dissimilatory reduction of nitrate to ammonium, and nitrification in a bioturbated estuarine sediment as measured with $\mathrm{N}$ and microsensor techniques. Applied and Environmental Microbiology 58, 303-313.

Bossio, D.A., Fleck, J.A., Scow, K.M., Fujii, R., 2006. Alteration of soil microbial communities and water quality in restored wetlands. Soil Biology \& Biochemistry 38, 1223-1233.

Bossio, D.A., Scow, K.M., 1998. Impacts of carbon and flooding on soil microbial communities: phospholipid fatty acid profiles and substrate utilization patterns. Microbial Ecology 35, 265-278.

Bossio, D.A., Scow, K.M., Gunapala, N., Graham, K.J., 1998. Determinants of soil microbial communities: effects of agricultural management, season, and soil type on phospholipid fatty acid profiles. Microbial Ecology 36, 1-12.

Bremner, J., 1996. Nitrogen-total. Methods of soil analysis. Part 3, 1085-1121.

Cao, Y., Fu, S., Zou, X., Cao, H., Shao, Y., Zhou, L., 2010. Soil microbial community composition under Eucalyptus plantations of different age in subtropical China. European Journal of Soil Biology 46, 128-135.

Chang, C., Xie, Z.Q., Xiong, G.M., 2011. The effects of three gorges reservoir water storage on the physical and chemical properties of soil. Ziran Ziyuan Xuebao 26, 1236-1244.

Clegg, C.D., Lovell, R.D., Hobbs, P.J., 2003. The impact of grassland management regime on the community structure of selected bacterial groups in soils. FEMS Microbiology Ecology 43, 263270.

Drenovsky, R.E., Vo, D., Graham, K.J., Scow, K.M., 2004. Soil water content and organic carbon availability are major determinants of soil microbial community composition. Microbial Ecology 48, 424430.

England, L.S., Lee, H., Trevors, J.T., 1993. Bacterial survival in soil: effect of clays and protozoa. Soil Biology \& Biochemistry 25, 525531.

Fernandes, M.F., Saxena, J., Dick, R.P., 2013. Comparison of wholecell fatty acid (MIDI) or phospholipid fatty acid (PLFA) extractants as biomarkers to profile soil microbial communities. Microbial Ecology 66, 145-157.

Fenchel, T and Finlay, B.J, 1995. Ecology and Evolution in Anoxic
Worlds. Oxford University Press, Oxford, UK.

Imlay J A, 2002. How oxygen damages microbes: oxygen tolerance and obligate anaerobiosis. Advances in Microbial Physiology 46 (1):111-153.

Fierer, N., Schimel, J.P., 2002. Effects of drying-rewetting frequency on soil carbon and nitrogen transformations. Soil Biology \& Biochemistry 34, 777-787.

Findlay, R.H., Dobbs, F.C., 1993. Quantitative description of microbial communities using lipid analysis. Handbook of methods in aquatic microbial ecology 32, 271-284.

Findlay, R.H., Trexler, M.B., Guckert, J., White, D.C., 1990. Laboratory study of disturbance in marine sediments: response of a microbial community. Marine Ecology Progress Series 62, 121-133.

Frindte, K., Allgaier, M., Grossart, H.P., Eckert, W., 2016. Redox stability regulates community structure of active microbes at the sediment-water interface. Environmental Microbiology Reports 8, 798-804.

Guckert, J.B., Antworth, C.P., Nichols, P.D., White, D.C., 1985. Phospholipid, ester linked fatty acid profiles as reproducible assays for changes in prokaryotic community structure of estuarine sediments. FEMS Microbiology Ecology 31, 147-158.

Guenet, B., Lenhart, K., Leloup, J., Giusti-Miller, S., Pouteau, V., Mora, P., Nunan, N., Abbadie, L., 2012. The impact of long-term $\mathrm{CO}_{2}$ enrichment and moisture levels on soil microbial community structure and enzyme activities. Geoderma 170, 331-336.

Haberer, C.M., Rolle, M., Cirpka, O.A., Grathwohl, P., 2012. Oxygen transfer in a fluctuating capillary fringe. Vadose Zone Journal 11, 811-822.

Heintze, S.G., 1934. The use of the glass electrode in soil reaction and oxidation-reduction potential measurements. Journal of Agricultural Science 24, 28-41.

Ibekwe, A.M., Kennedy, A.C., 1998. Phospholipid fatty acid profiles and carbon utilization patterns for analysis of microbial community structure under field and green house conditions. FEMS Microbiology Ecology 26, 151-163.

Langer, U., Rinklebe, J., 2009. Lipid biomarkers for assessment of microbial communities in floodplain soils of the Elbe River (Germany). Wetlands 29, 353-362.

Li, N., Yao, S.H., Qiao, Y.F., Zou, W.X., You, M.Y., Han, X.Z., Zhang, B., 2015. Separation of soil microbial community structure by aggregate size to a large extent under agricultural practices during early pedogenesis of a Mollisol. Applied Soil Ecology 88, 9-20.

Lüdemann, H., Arth, I., Liesack, W., 2000. Spatial changes in the bacterial community structure along a vertical oxygen gradient in flooded paddy soil cores. Applied and Environmental Microbiology 66, 754-762.

Mentzer, J.L., Goodman, R.M., Balser, T.C., 2006. Microbial response over time to hydrologic and fertilization treatments in a simulated wet prairie. Plant and Soil 284, 85-100.

Moche, M., Gutknecht, J., Schulz, E., Langer, U., Rinklebe, J., 2015. Monthly dynamics of microbial community structure and their controlling factors in three floodplain soils. Soil Biology \& Biochemistry 90, 169-178.

Navarrete, A., Peacock, A., Macnaughton, S.J., Urmeneta, J., MasCastellà, J., White, D.C., Guerrero, R., 2000. Physiological status and community composition of microbial mats of the Ebro Delta, 
Spain, by signature lipid biomarkers. Microbial Ecology 39, 92-99.

Nelson, D., Sommers, L., 1996. Total carbon, organic carbon and organic matter. In 'Methods of soil analysis. Part 3. Chemical methods. Soil Science Society of America: Madison, WI, (Ed. D.L. Sparks) pp. 961-1010.

Nikolausza, M., Székely, A., Rusznyák, A., et al, 2008. 2008, Diurnal redox fluctuation and microbial activity in the rhizosphere of wetland plants. European Journal of Soil Biology 44, 324-333.

Or, D., Smets, B.F., Wraith, J.M ., Dechesne, A., Friedman, S.P., 2007. Physical constraints affecting bacterial habitats and activity in unsaturated porous media - a review. Advances in Water Resources 30,1505-1527.

Orwin, K.H., Wardle, D.A., Greenfield, L.G., 2006. Context-dependent changes in the resistance and resilience of soil microbes to an experimental disturbance for three primary plant chronosequences. Oikos 112,196-208.

Pett-Ridge, J., Firestone, M.K., 2005. Redox fluctuation structures microbial communities in a wet tropical soil. Applied and Environmental Microbiology 71, 6998-7007.

Picek, T., Šimek, M., Šantrůčková, H., 2000. Microbial responses to fluctuation of soil aeration status and redox conditions. Biology and Fertility of Soils $31,315-322$.

Rinklebe, J., Langer, U., 2006. Microbial diversity in three floodplain soils at the Elbe River (Germany). Soil Biology \& Biochemistry, 38, 2144-2151.

Satpathy, S.N., Rath, A.K., Ramakrishnan, B., Rao, V.R., Adhya, T.K., Sethunathan, N., 1997. Diurnal variation in methane efflux at different growth stages of tropical rice. Plant and Soil 195, 267 271.

Shamsi, I.H., 2012. Effects of irrigation patterns and nitrogen fertilization on rice yield and microbial community structure in paddy soil. Pedosphere 22, 661-672.

Shen, Z., Chen, L., Hong, Q., Qiu, J., Xie, H., Liu, R., 2013. Assessment of nitrogen and phosphorus loads and causal factors from different land use and soil types in the Three Gorges Reservoir Area. Science of the Total Environment 454-455, 383 392.

Silver, W.L., Lugo, A.E., Keller, M., 1999. Soil oxygen availability and biogeochemistry along rainfall and topographic gradients in upland wet tropical forest soils. Biogeochemistry 44, 301-328.

Sinclair, J.L., Ghiorse, W.C., 1989. Distribution of aerobic bacteria, protozoa, algae, and fungi in deep subsurface sediments. Geomicrobiology Journal 7, 15-31.

Song, Y., Deng, S.P., Acosta-Martinez, V., Katsalirou, E., 2008. Characterization of redox-related soil microbial communities along a river floodplain continuum by fatty acid methyl ester (FAME) and 16S rRNA genes. Applied Soil Ecology 40, 499-509.

Sundh, I., Börjesson, G., Tunlid, A., 2000. Methane oxidation and phospholipid fatty acid composition in a podzolic soil profile. Soil Biology \& Biochemistry 32, 1025-1028.

Teichert, A., Böttcher, J., Duijnisveld, W.H.M., 2000. Redox measurements as a qualitative indicator of spatial and temporal variability of redox state in a sandy forest soil. Redox. Springer Berlin Heidelberg, 95-110.

van Aarle, I.M., Olsson, P.A., 2003. Fungal lipid accumulation and development of mycelial structures by two arbuscular mycorrhizal fungi. Applied and Environmental Microbiology 69, 6762-6767.

Vestal, J.R., White, D.C., 1989. Lipid analysis in microbial ecology: quantitative approaches to the study of microbial communities. Bioscience 39, 535-541.

Wilms, R., Sass, H., Köpke, B., Köster, J., Cypionka, H., Engelen, B., 2006. Specific bacterial, archaeal, and eukaryotic communities in tidal-flat sediments along a vertical profile of several meters. Applied and Environmental Microbiology 72, 2756-2764.

Wu, J.S., He D.Y., 1994. Soil organic matter and its turnover dynamic change. Soilfertility and fertilization for crops in southern China. Beijing: Science \& Technology Press (吴金水, 何电源. 土壤有机质 及其周转动力学 $[\mathrm{J}]$. 中国南方土壤肥力与栽培植物施肥. 北京: 科学 出版社) 62: 1994.28-62.

Ye, C., Li, S., Zhang, Y., Zhang, Q., 2011. Assessing soil heavy metal pollution in the water-level-fluctuation zone of the Three Gorges Reservoir, China. Journal of Hazardous Materials 191, 366-372.

Zhou, Y.J., Qiu, J.X., Wang, J., 2010. Evaluation of ecological environmental vulnerability in the xiaolan area of the three gorges reservoir area. Journal of Ecology 30, 672-673. 